\title{
Exploring the Writing Process of Indonesian EFL Students: The Effectiveness of Think-Aloud Protocol
}

\author{
Imelda Hermilinda Abas (Corresponding author) \\ Universiti Utara Malaysia, College of Arts and Sciences, 06010 Sintok, Kedah Malaysia \\ E-mail: imelabas@yahoo.com \\ Noor Hashima Abd Aziz \\ Language Department, School of Education and Modern Languages, Universiti Utara Malaysia, College of Arts and \\ Sciences, 06010 Sintok, Kedah Malaysia \\ E-mail: noor934@uum.edu.my
}

Doi:10.7575/aiac.alls.v.7n.2p.171

URL: http://dx.doi.org/10.7575/aiac.alls.v.7n.2p.171
Received: 29/11/2015

Accepted: 24/01/2016

\begin{abstract}
The objectives of this study were to explore the writing process of the Indonesian English as a Foreign Language (EFL) students and to find out the effectiveness of using think-aloud protocol to understand the writing process. The data were obtained from six proficient EFL students who were doing Postgraduate English Language Studies Program in Indonesia. The participants were selected based on the following criteria: had completed a minimum of two academic writing courses, had written a thesis in English, had taught English for more than two years and considered as proficient writers based on IELTS result. The finding of the study showed that all of the participants went through the following writing process: prewriting, planning, drafting, pausing, reading, revising, editing and publishing. In addition, the thinkaloud protocol had different effects on the participants. Five of the participants admitted that the think-aloud protocol had a positive effect because it helped them in organizing their thoughts and ideas. However, only one participant found thinking aloud made her difficult to focus on the writing task due to the demand to verbalize and write at the same time.
\end{abstract}

Keywords: think-aloud protocol, writing process, proficient writers, English as a Foreign Language (EFL)

\section{Introduction}

In today's global world, English is one of the most widely spoken languages and it has strengthened the social and economic exchange between people of different communities and cultures. English is used in education, media, sports and business. The English language skills can be categorized into two groups: listening and reading as the language input, and speaking and writing as the language output. Speaking and listening come naturally for second language (L2) or foreign language (FL) learners because the learners need to communicate using the target language. On the contrary, the language learners need someone to teach them how to write in the target language because it involves aspects such as types of writing, grammatical structure and writing strategies. In other words, the language learners know how to speak and listen in the target language easily and rather quickly than knowing how to write.

Writing is a skill needed in education for professional success especially at the work place (Applebee, Langer, Mullis, Latham \& Gentile, as cited in Hamman, 2005; Johannesen, 2001). A research done by Gardner and Nesi (2012) identified thirteen genres families in writing: case study, critique, design specification, empathy writing, essay, exercises, explanation, literature survey, methodology recount, narrative recount, problem question, proposal and research report (p. 188). Writing can be defined as "a way for students in all content areas to make meaning for themselves" (Bereiter \& Scardamalia, 1987, p.5) and learning how to think and communicate in their particular domains (Herrington, 1985).

According to De la Paz and Graham (2002), writing is regarded as a challenging task because it involves the composition of a variety of cognitive resources and problem solving activities. Moreover, writing is complicated and demands higher thinking abilities (Alhosani, 2008). Williams (2005) suggests two important basic principles that are closely related to L2 writing. Firstly, both linguistic competence and writing skill are required in learning to write well because they support each other and simultaneously help to improve the second language learners' writing skills. Moreover, writing skill cannot be developed spontaneously in a short period of time. For instance, a native speaker or a second language learner who is competent in his/her language may not be competent in his/her ability to write. Secondly, second language learning is an extended process, for many L2 students it is a never-ending process. For most people, acquiring a second language is not the same as acquiring a first language (Williams, 2005). Children who live in an environment with plenty of language inputs and examples learn fast in acquiring their first language. In addition, the language is used in the children's daily lives. On the contrary, children who do not have the chance of using L2 or FL in their daily lives would acquire them slower. 
Some aspects that have been associated with writing problems in second language or foreign languages are different cultural background (Imtiaz, 2003; McCharthy, 1992; Sadik, 2009), different textual patterns (McCharthy, 1992) and different writing approach (process and product of L2 writing) (Angelova, 1999). Among the problems related to the process and product of writing are language competence, first language writing competence, use of cohesive devices, metacognitive knowledge about writing task, writing strategies and writer's personal characteristics.

\section{Writing in English in Indonesia}

In Indonesia, English is taught as a foreign language. Although most of the students, especially those at tertiary level, have learnt English since primary school, they still find it difficult to express their ideas in English, particularly in academic writing. A study done by Sadik (2009) on Indonesian university students found that they were taught several steps of writing such as prewriting, planning, drafting, revising and editing. However, she discovered that the students still faced problems in writing such as limited knowledge of writing strategies, grammatical structure, and low interest in writing. She also discovered that the students were not aware that writing is a process and cannot be done instantly. Moreover, Mistar, Zuhairi and Parlindungan (2014) conducted a study on secondary school students and found that the knowledge of writing of the school students was very low. The students mostly used self-monitoring strategies which occurred only in the editing phase such as correcting mistakes by reading, rewriting, noticing mistakes and paying a great deal of attention to linguistic aspects of English learning. In addition, a study done by Setyono (2014) on the teaching of writing at the high school level found that the product-based approach of writing instruction was still being used by teachers in most school levels in Indonesia. The product-based approach is characterized by the linear model of instruction in which students are not given adequate time and opportunities to produce final products of writing through revising process.

English as a Second Language (ESL) writing research has given more importance on the writing process in ESL writing (Silva \& Matsuda, 2005). For example, a study conducted by Winer (1992) found that writing task using the process approach could change the students' negative attitudes and behaviour towards writing. These findings inspired the researcher to: 1) explore the writing process of the Indonesian English as a Foreign Language students; 2) find out the effectiveness of using think-aloud protocol to understand the writing process.

\section{Models of Writing}

Since 1980, research on composition study have widely opened the door for researchers to construct practical models of writing process. Among the most significant models of writing process were the ones by Flower and Hayes (1981) and Bereiter and Scardamalia (1987). There are three basic characteristics in Flower and Hayes' writing process model. Firstly, it is structurally classified, with sub-process in each process except for the translating phase. For instance, planning includes developing ideas, goal-setting and organizing, and reviewing includes reading and editing. Secondly, it is organized separately, in that the three phases, namely, planning, translating and reviewing support the accomplishment of the written text and each process may take place in any order. For instance, a writer may compose without planning or may review without planning. Thirdly, these three phases connect and interact with the task environment and the writer's long-term memory as important sources of information. The task environment, consists of the linguistics problems (that limit the alternative of logical coherence, argumentation, lexical and grammatical decisions), which is presented in the topic and the audience of the writing piece and the already produced text. Furthermore, a warehouse of knowledge of projected audience, the topic and plan for writing are described as the writer's long term memory.

However, Bereiter and Scardamalia's (1987) model of writing comprises two main aspects, namely, knowledge telling strategy and knowledge transforming strategy. The model makes a distinction between proficient and novice writers, and the complexity of the task among skilled writers. Knowledge telling strategy refers to novice writers while the knowledge transforming strategy refers to proficient writers. Proficient writers employ significantly different and more sophisticated writing strategies than those of novice writers. Some proficient writers put more effort to solve the content problem and rhetorical problem in difficult writing task than some others. Grabe and Kaplan (1996) suggest that the concepts of knowledge telling and knowledge transformation as constructive concept in writing pedagogy and writing assessment. However, in the model there is no description or explanation on "how writers actually make the cognitive transition to a knowledge-transforming model ... what occurs in the intervening stages and whether the process is the same for all learners" (Hyland, 2002, p. 28).

On the other hand, Williams (2003) proposes an extended writing process model that is known as the phase model. The phase model comprises eight processes of writing: prewriting, planning, drafting, pausing, reading, revising, editing and publishing. Each process consists of different activities that are associated with effective writing and recursive nature of the writing process (Williams, 2003). The prewriting stage has various activities, such as discussion, outlining, freewriting, and journals that may support the writers in developing ideas. The planning stage is where we can see how the writers' ideas integrate with the purpose of the paper. Next, at the drafting stage, the writers put together their ideas into a specific order. Pausing and reading stages occur simultaneously, signified by minutes of silence. Then, during the revising stage, the writers refine the organizations and expressions in their composition. Later, at the editing stage, the writers engage in sentence level concerns such as spelling, punctuation, and usage. Finally, during the publishing stage, the writers share their final composition with the public.

However, not all writers experience the corresponding process or activities. What may work for one writer might not work for another. Williams (2003) proposes that all writers engage in these processes to some extent. What works 
successfully for some students may not work well for others, and what functions well for one assignment may not be compatible to another. Some writers combine various activities, while others use only one. Therefore, student writers should explore the writing strategies to identify what works best for them. Williams' (2003) process model suggests that a finished composition is "the result of the complex interaction of activities that include several stages of development" (p. 106). Although, not every writing task moves across every stage, these stages of writing process indicate how writing successfully develops in general. Williams (2003) suggests that the writing process such as planning, drafting, and revising, has influential states. However, these processes are repeatedly modified which implies that, "students revise as they draft, they plan as they edit; and so forth" (p.120).

The present study used Williams's (2003) model of writing as a guide to conduct this research due to a few reasons: first, in the process-oriented classrooms, the focus is on the writing process; second, the instruction is top-down, not bottom-up, which means that the focus is on producing the entire papers but not on grammar or parts of the papers; third, the purpose of the process instruction is to modify the student writers' behaviour in order to match with the good writers.

\section{The Think Aloud Protocol as a Data Collection Technique}

This qualitative case study employed four data collection techniques: observations, interviews, think-aloud protocol, and writing samples. However, for this particular article, only the think-aloud protocol will be discussed.

Think-aloud protocols have been widely used in the areas of psychology and cognitive science as a verbal-report method of generating concurrent verbalization (Yoshida, 2008). In addition, the think-aloud protocols have been applied in second language acquisition research to study the cognitive process involved in the use and acquisition of language. Reading, writing and testing are the major areas of Second Language Acquisition where the think-aloud protocols are applied. Yoshida (2008) stresses that the protocols provide information for the language acquisition researchers such as types of strategies utilized by students in interacting with L2 tasks and the types of process that are expected in a specific type of verbal reports.

Pressley and Afflerbach (1995) point out that there are three advantages of the think-aloud protocol; (1) it supports investigation of data on cognitive processes and participants' responses directly; (2) it offers access to the decisionmaking and reasoning processes underlying sophisticated cognition; and (3) it allows for cognitive processes and affective processes to be coded and analyzed. Furthermore, Raimes (1985) found that the protocol is capable of providing more information on the student writers than any other analysis of products or observation of the writing process. Thus, she claims that "think-aloud composing was simply too good a tool not to be used" (Raimes, 1985, p. 234) because it provides insights into the writers' cognitive processes, their responses and thinking at particular stages of the writing process.

Thinking-aloud protocols technique in writing research includes requesting the writer simply to think aloud as he or she writes (Hayes \& Flower, 1986). The participants are required to say whatever that they are thinking, even irrelevant statements or opinions. The most important thing is that the participants should not try to analyze what they are doing. In this study, some procedures were used when doing the think-aloud protocol. Before commencing the think-aloud protocol, the technique was introduced to the participants. During the think-aloud process, the researcher actively participated in terms of explaining the instructions about the technique and kept reminding the participants to keep talking while performing the writing task. In addition, the participants were recorded using a video camera to think aloud as they composed, so that the resulting protocols can be analyzed. The protocol was conducted with each student at a time individually. Each participant was given sixty minutes to compose.

The think-aloud protocol was conducted in one of the classrooms at the Language Center of Hasanuddin University, Indonesia. The class was equipped with a few desks, a big whiteboard, and air condition. Although the room was small, it was comfortable.

The participants for this research were postgraduate students in Indonesia who were selected based on the following criteria: (1) they were considered to have enough skill in English writing, after completing two academic writing courses; (2) they had written an unpublished thesis during their undergraduate studies and they will write their Master thesis in English as a prerequisite to complete their master degree; (3) they had taught English for more than two years; (4) they were classified as proficient writers based on IELTS result.

To decide on the proficient writers, a preliminary test of International English Language Testing System (IELTS) Writing task 2 was administered. IELTS was selected because it is a recognized international standardized test of English language proficiency for non-native English speakers. It is also commonly used at universities in Indonesia. Thus, the students are familiar with the test. The results of the writing tasks were collected and graded by the researcher and two inter-raters. The writing tasks were evaluated on six traits: Idea \& Content, Organization, Voice, Word Choice, Sentence Fluency, and Convention. Each trait was awarded 6 points. Therefore, the total score for each writing sample was 36 points. The purpose of grading the task was to determine the students' level of writing proficiency in English.

From the 80 students who did the preliminary writing tasks, the researcher found only seven students who obtained a score above 32. Thus, these students were categorized as proficient writers. However, from the seven students, only six were willing to participate in the study. Therefore, the participants of this study consisted of one male student, Erza (pseudonym) and five female students: Prita, Dani, Norma, Suka and Irza (pseudonyms). All were postgraduate full time students in their third semester at the Faculty of Cultural Sciences. 


\section{Findings}

\subsection{The Writing Process}

The topic of the composition given to the participants was "Children below sixteen should not be allowed in public places after midnight". The participants were required to write a composition by stating their opinion of agreeing or disagreeing with the issue, and providing reasons for their stand.

Findings from the think-aloud protocol show that all of the participants went through the following process in writing their composition: prewriting, planning, drafting, pausing, reading, revising, editing and publishing (Williams, 2003). However, only Erza and Dani did not go through the planning stage after their prewriting stage. In general, pausing and reading occurred concurrently, as well as revising and editing.

\subsubsection{Prewriting stage}

All the six participants of this research were engaged in this idea-generating activity i.e. prewriting to assist them in focusing on their writing task (Farrell, 2006). The activities that were identified at this stage were brainstorming, outlining, clustering, talk-write and freewriting. Norma and Erza performed the most number of prewriting activities among the participants. Erza prewrote his composition by using talk-write where he generated ideas by talk-write, which included brainstorming and organizing the paragraphs verbally (Williams, 2003). He spoke his ideas loudly. He spent about five minutes brainstorming his ideas before starting with the drafting stage. On the other hand, Norma prewrote by using freewriting that involves writing non-stop for five, ten or fifteen minutes (Williams, 2003). Freewriting aims to discover things to say about a topic rather than to plan the paper, involving writing nonstop for five, ten to fifteen minutes, generating ideas even if the writer cannot think of anything meaningful to say (William, 2003, p. 109). In Norma's case, freewriting occurred recursively. At the prewriting stage, she wrote continuously the ideas that she had for the first paragraph. When she found good ideas she used them as the basis for her first paragraph. She would then start writing her first paragraph, and repeating the same process for the second and the third paragraphs. Conversely, Dani, Prita, Suka and Irza utilized brainstorming, outlining and clustering where they prewrote by drawing a kind of mapping sheet consisting of ideas they had. The mapping sheet consisted of outlines as the main ideas in each paragraph that were followed by four to five words related to each outline as the supporting details or examples.

\subsubsection{Planning stage}

When the participants had finished the prewriting stage activities, they went over their prewriting work before starting their first draft. In this research, the planning stage is an extension of the prewriting stage where some of the activities were performed. At this stage, the participants checked the ideas generated previously during the prewriting activities to make sure they matched with the main topic. From the findings of the research, the researcher discovered that not all of the participants went through the planning stage in their composition process. For instance, when Dani and Erza had completed their prewriting activity, they immediately started drafting. This prompted the researcher to ask Erza and Dani why they skipped the planning stage. They replied that it was due to the limited time given. Erza chose to verbally construct and organize his ideas without writing them down, while Dani mostly relied on his brainstorming list. However, if there is no limited time given, such as doing a take home assignment, Erza would have done the prewriting stage in a different way, that is, he would brainstorm his ideas related to the topic, dismiss the words that are too difficult to include in his writing, classify the words that belong together, and choose which ones go first, second, and so on.

At the planning stage, Prita and Suka used brainstorming list whereas Irza used mind mapping. Prita and Suka reviewed their brainstorming list to make sure that they included those ideas that they had during the prewriting. During the prewriting they wrote down their ideas and then classified them into groups that signify the paragraphs. However, Irza explained that when she finished her prewriting stage, she reviewed her ideas by mapping them on the sheet she wrote to make sure that she included all the ideas that she had. The four outlines that she made in the prewriting stage also functioned as a guide to organize her paragraphs. She planned by deciding which outline should be written as her first, second and third paragraph. Irza explained that the mind mapping was also used as her planning.

Norma was found to use a unique planning activity. The planning stage overlapped with Norma's prewriting stage when some of the activities were performed. Norma conducted freewriting as her prewriting activity. She rechecked her ideas to make sure they matched the topic. For example, the outline she made for the first paragraph consisted of major points that she wanted to address in the paper. On occasions, she would add some details to her ideas. In planning, she would think about the readers, the organization, and relate the topic to her knowledge and experience.

\subsubsection{Drafting Stage}

The participants wrote their first draft as soon as they finished the prewriting or the planning stage. Generally, the participants knew exactly what they wanted to do at this stage. They transformed their ideas into sentences, and on some occasions, they copied what they had written previously during the prewriting stage by using linking words to join the sentences.

After finishing the prewriting or the planning stage, all of the participants immediately started to write the introduction, body and conclusion paragraphs. Each paragraph consisted of a thesis statement with three to four supporting details. For instance, Erza started writing the introduction section by providing the definition of children in the Indonesian context, followed by his argumentation and supporting details, and the conclusion. 
At the drafting stage, many activities were performed. Pausing, reading, revising, and editing activities which occurred overlapped at this stage. When the researcher prompted a question on why these activities occurred at this stage, each participant gave different reasons. For example, Prita explained that the first paragraph should cover the general things of what the paper should be all about. When she noticed that her paragraph was too specific, she revised and generalized her ideas so that the readers could see what she wanted them to see in her paper. In addition, Irza said that during the drafting stage, she paused and read her work to search for spelling mistakes and to think about the correct word choice, linking words as well as to think about ways to elaborate her ideas. At the drafting stage, Dani paused and read her brainstorming ideas to stay on tract and to arrange her ideas. To sum up, Prita, Irza and Dani performed reading, revising and editing at the drafting stage.

On the other hand, Norma performed freewriting that overlapped and recursively occurred at the drafting stage. When Norma finished her freewriting for the first paragraph, she wrote down her ideas and connected them together into sentences and paragraphs. Then, she read what she had written and continued to do freewriting for the second paragraph as well as the third paragraph. The freewriting activity occurred recursively throughout her writing. At this stage, the researcher noticed that only Norma, Suka and Dani wrote their second drafts. These drafts were error-free version.

\subsubsection{Pausing Stage}

Pausing occurred frequently throughout the writing process. In general, pausing happened at two stages. The first pausing appeared at the drafting stage, indicated by moments of silence when the participants were examining what they had written, searching for correct word choices and ideas of what to write next, revising and editing the task. The second pausing appeared when the participants finished their drafts, indicated by silent moments of going through their writing aimed at editing and revising.

\subsubsection{Reading Stage}

The reading stage was found to occur concurrently with the pausing stage. Reading was performed with the intention of going through what had been written so far, to make sure that all the ideas were covered in the writing, to add more ideas, and to look for errors in spelling, grammar and punctuation. Throughout the writing process, the participants were seen reading their writing task several times. When the researcher asked the aim of rereading the task, Erza explained that it was done to refresh what he wanted to write and to remind him not to go off the topic. For all the participants, reading was also used to check for cohesiveness of the sentences.

Reading also occurred in Norma's writing process. The first reading occurred at the prewriting stage when Norma finished her first paragraph. Norma explained that she would reread what she had written and connect all of her ideas to make sure that the ideas in the first paragraph were linked with the second and the third paragraphs. The second reading occurred when Norma finished writing each paragraph. She would go back and read the paragraph that she had just written. She explained that she reread the paragraphs to find errors, like vocabulary, plurals, agreement, tenses, and redundant words.

Upon writing the second draft, Dani, Norma and Suka read again their drafts to make sure all the ideas they had were covered and to make sure that the second draft was error-free. Dani explained that on her second draft, although she wrote everything the way she wanted, she still needed to read and make sure all the ideas were coherent and to check for grammar and punctuation in order to make the second draft error-free.

\subsubsection{Revising Stage}

Revising is a significant stage in the writing process. Revising involves making changes that enhance the match between plan and text (Williams, 2003). Revising includes reconsidering the arguments, reviewing the evidence, refining the purpose, reorganizing the presentation, and reviving stale prose. From the findings obtained through the think-aloud protocol, the researcher discovered that the revising stage occurred much earlier, mostly in the pausing and reading stage. At this stage, the participants would usually start with reading what they had written in order to make sure the text match with their plan.

The revising stage also occurred concurrently with the editing stage. All of the six participants would read thoroughly the paragraphs they had written, checking if all the ideas were covered in their writing, deleting and adding some ideas, and making sure that the ideas were not redundant. Suka, Norma and Dani rewrote their paragraphs in their second draft to make sure they were readable and neat. However, for the second draft, they did not make any changes.

\subsubsection{Editing Stage}

At this stage, the participants dealt with sentence level concerns such as spelling, punctuation and usage. From the findings, the participants seemed to focus on sentence correctness, and the goal was to write error free composition. The editing stage was done by rereading all the paragraphs by checking the punctuation, spelling and grammar errors, and paying attention to the sentence structure. As mentioned earlier, Suka, Norma and Dani rewrote their second draft to make sure it was error-free. However, for the second draft, they did not make any changes. From the findings and analysis, the researcher noted that Erza, Prita and Irza made very few errors. However, Irza seemed not to be bothered with capitalization of her text. In most sentences, she used small letters to begin her sentences.

\subsubsection{Publishing Stage}

The writing samples of the participants were allowed to be published by simply handing it to the researcher and allowing her to make copies and publish them in her study. Whether their papers received low or high scores, the six 
participants realized that "writing is not just a finished product but also a process of discovering their own thoughts" (Farrell, 2006:72). The findings of this study are similar with Raimes (1985) where she found that in composing, experienced writers considered the purpose and audience, consult their own background knowledge, let their ideas develop, read back over what they have written to relate with their plan. This process is recursive in nature, a "cyclical process during which writers move back and forth on a continuum discovering, analysing and synthesizing ideas" (Hughey, Wormuth, Hartfiel \& Jacobs, 1983, p.28).

\subsection{The Effectiveness of the Think-Aloud Protocol}

Since the participants of the study were not familiar with the think-aloud protocol procedures, they were given time to practice before conducting the real protocol. From the findings, the researcher noted that the effect of thinking aloud was different to each participant.

In this study, the think-aloud protocol has been found to be a good data collection technique to obtain verbalized reactions towards the task at hand, that is, writing a composition. The writing process was described by the participants while writing the composition assigned.

For Erza, thinking aloud made him think harder about the topic before making his stand of agreeing or disagreeing with the topic of the composition. He explained that when he read the task, at first, he agreed with the topic that "Children below 16 years old shouldn't be allowed in public places after midnight unless accompanied by adults". However, after going through the thinking aloud procedure, Erza changed his mind about his stand. He stated that during the protocol, the more he listened to himself talking, the more he realized that his opinion was somehow selfish because he was thinking from adults or parents' perspectives. Although Erza changed his opinion from agreeing to disagreeing with the task, the writing process he went through did not change. It can be concluded that verbalization through think-aloud protocol helped Erza to decide on his stand. Thus, the protocol made the cognitive process become observable. Similar result was also found in the research conducted by Amizura and Noor Hashima (2013), whereby the participant was asked to give verbal reports of his cognitive processes while reading two short stories. The participant's cognitive processes during the progress of the reading tasks become observable by using think aloud protocol as a data collection technique.

Prita admitted that thinking aloud helped her in her writing. Although the think-aloud protocol procedure was new to her, Prita discovered it helped her to plan. Similar findings were also found in Dani, Irza and Suka's think-aloud while writing the task. In general, Dani and Suka were able to articulate what they thought while writing. However, they had to be reminded to keep on talking aloud while writing. The think-aloud protocol helped Dani to organize her writing. Dani found the procedure of the think aloud protocol used in writing to be quite different from the writing activities in the class due to the amount of attention she got in her writing. Thus, she could improve the focus of her writing. The overall procedures of Irza's think-aloud went smoothly. For the most part, she was able to articulate her thoughts while writing although at times she had to be reminded to keep on talking while writing. The think-aloud procedure brought positive effect on Irza's writing. She explained that the thinking aloud trained her to generate her ideas although normally it was difficult for her to do so. Thinking aloud allowed her to trace back what she thought about the topic because she could listen to herself while talking. Similar finding was found in Khatami, Heydariyan and Bagheri's (2014) study, where they found that think aloud stimulated the students to employ cognitive process and supported them to access the background knowledge of the text. To conclude, Prita, Dani, Irza and Suka found think aloud strategy helped them to improve their writing ability. Although Suka performed well in the think aloud procedure, she did not feel comfortable being recorded and claimed that unintentional activity might happen because of her nervousness.

On the contrary, Norma found the thinking-aloud procedure to bring a negative effect on her because it made her difficult to focus, presumably due to the demand of verbalization. She stated that it was hard to verbalize what she wanted to write. It was hard for her to focus on the writing task. This finding is similar to Ransdell's study (1995) where she examined the effect of thinking-aloud protocols on college students' narrative writing. The study was based on the theory proposed by Hayes and Flower (1983) where generating thinking-aloud protocols may lessen the ability to organize multiple writing subtasks, such as tracking the simultaneous subtasks of planning, generating text, and revising. Thus, the addition of generating think-aloud protocols verbally may be particularly challenging relative to cognitive tasks that demand fewer subtasks. The study found that the requirement of verbalization made the rate of the students' writing to be slower.

\section{Conclusion}

Findings of the study showed that all of the participants used the following writing process, which consisted of prewriting, planning, drafting, pausing, reading, revising, editing and publishing. This writing process was proposed by Williams (2003).

The effect of the think-aloud protocol was different to each participant. In general, this could probably be due to his or her unfamiliarity with the process. Erza found the procedure made him change his stand about the topic of the composition after going through verbalization of the task. This happened unintentionally. To Prita, Dani, Irza and Suka, thinking aloud helped them in their writing in terms of arranging their ideas, staying focus and generating ideas easier. On the contrary, Norma found the thinking-aloud procedure brought negative effect on her because it made her difficult to focus, presumably due to the demand of verbalization. 


\section{References}

Alhosani, N.M. (2008). Utilizing the writing process approach with English as a second language writers: A case study of five fifth grade of ESL Arab students (Doctoral dissertation). Retrieved from ProQuest Dissertation and Theses (3341499).

Amizura, H.M.R., \& Noor Hashima, A.A. (2013). Of village bomoh and the lottery: Content schemata influence on second language reading. Advances in Language and Literary Studies, 4(1), 42-50. DOI: 10.7575/aiac.alls.v.4n.1p.42

Angelova, M. (1999). An exploratory study of factors affecting the process and product of writing in English as a foreign language. Buffalo, NY: State University of New York.

Bereiter, C., \& Scardamalia, M. (1987). The psychology of written composition. Hillsdale, NJ: Lawrence Erlbaum.

De La Paz, S., \& Graham, S. (2002). Explicitly teaching strategies, skills, and knowledge: Writing instruction in middle school classrooms. Journal of Educational Psychology, 94(4), 687-698. Retrieved from http://psycnet.apa.org/doi/10.1037/0022-0663.94.4.687

Farrell, T.S.C. (2006). Succeeding with English language learners: A guide for beginning teachers. Thousand Oaks, CA: Corwin Press.

Flower, L. S., \& Hayes, J. R. (1981). A cognitive process theory of writing. College Composition and Communication, 32, 365-387. DOI: $10.2307 / 356600$

Gardner, S., \& Nesi, H. (2012). A classification of genre families in university student writing. Applied Linguistics, 34(1), 25-52. DOI: 10.1093/applin/ams024

Grabe, W., \& Kaplan, R. (1996). Theory and practice of writing. London: Longman.

Hamman, L. (2005). Self-regulation in academic writing tasks. International Journal of Teaching and Learning in Higher Education, 17(1), 15-26. DOI: 10.1093/applin/ams024

Hayes, J. R., \& Flower, L. S. (1983). A cognitive model of the writing process in adults (Final Report). Retrieved from ERIC website: http://files.eric.ed.gov/fulltext/ED240608.pdf

Hayes, J. R., \& Flower, L. S. (1986). Writing research and the writer. American psychologist, 41(10), 1106. DOI: 10.1037/0003-066X.41.10.1106

Herrington, A. J. (1985). Writing in academic settings: A study of the contexts for writing in two college chemical engineering courses. Research in the Teaching of English, 331-361. Retrieved from http://www.jstor.org/stable/40171066

Hughey, J.B., Wormuth, D.R., Hartfiel, V.F., \& Jacobs, H. (1983). Teaching ESL composition: Principles and techniques. Rowley, MA: Newbury House Publishers, Inc.

Hyland, K. (2002). Genre: Language, context, and literacy. Annual Review of Applied Linguistics, 22, 113-135. DOI:_http://dx.doi.org/10.1017/S0267190502000065

Imtiaz, S. (2003). Cognitive processes in writing: Exploring the strategies used by second and foreign language learners of English [monograph]. Language in India, 3 (4 April, 2003). Retrieved from http:// languageinindia.com /april2003/cognitivewriting.html

Johannesen, L.R. (2001). Teaching thinking and writing for a new century. English Journal, 90, 38-46. DOI: $10.2307 / 822054$

Khatami, M., Heydariyan, Y., and Bagheri, V. (2014). Investigating the effect of think aloud strategy on reading comprehension ability among EFL university students. International Journal of Language Learning and Applied Linguistics World (IJLLALW), 5(1), 381-393.

McCharthy, M. (1992). Discourse analysis for language teacher. Cambridge, UK: Cambridge University Press.

Mistar, J., Zuhairi, A., and Parlindungan, F. (2014). Strategies of learning English writing skill by Indonesian senior high school students. Arab World English Journal, 5(1), 290-303. Retrieved from: http://eds.a.ebscohost.com/95382057

Pressley, M., \& Afflerbach, P. (1995). Verbal protocols of reading: The nature of constructively responsive reading. Hillsdale, NJ: Lawrence Erlbaum.

Raimes, A. (1985). What unskilled ESL students do as they write: A classroom study of composing. Tesol Quarterly, 19(2), 229-258. DOI: $10.2307 / 3586828$

Ransdell, S. (1995). Generating thinking-aloud protocols: Impact on the narrative writing of college students. The American journal of Psychology, 108(1), 89-98. DOI: 10.2307/1423102

Sadik, A. (2009). Cognitive and metacognitive writing strategies and their relations to writing performance of EFL learners (Unpublished Doctoral Dissertation). Makassar, Indonesia: Universitas Hasanuddin.

Setyono, B. (2014). Approaches in teaching writing designed by high school English teachers in Indonesia. International Journal of Sciences: Basic and Applied Research, 14(1), 477-494. Retrieved from http://gssrr.org/index.php?journal=JournalOfBasicAndApplied 
Silva, T., \& Matsuda, P. K. (Eds.), (2005). On second language writing: Perspectives on the process of knowledge construction. Mahwah, NJ: Lawrence Erlbaum.

Williams, J. (2005). Teaching writing in second and foreign language classrooms. USA: McGraw Hill.

Williams, J.D., (2003). Preparing to teach writing: Research, theory, and practice ( $3^{\text {rd }}$ Ed.). Mahwah, NJ: Lawrence Erlbaum.

Winer, L. (1992). Spinach to chocolate: Changing awareness and attitudes in ESL writing teachers. TESOL Quarterly, 26(1), 57-79. DOI: $10.2307 / 3587369$

Yoshida, M. (2008). Think-aloud protocols and type of reading task: The issue of reactivity in L2 reading research. In Melissa Bowles, Rebecca Foote, Silvia Perpinan, \& Rakesh Bhatt (Eds.), Selected Proceedings of the 2007 Second language Research Forum (pp. 199-209). Somerville, MA: Cascadilla Proceedings Project. Document \#1745. 